\title{
eCommons@AKU
}

April 2017

\section{Expanding access to healthcare in South Asia}

Shehla Zaidi

Aga Khan University, shehla.zaidi@aku.edu

Prasanna Saligram

Public Health Foundation of India, New Delhi, India

Syed Ahmed

BRAC, Dhaka, Bangladesh

Egbert Sonderp

Karolinska Institutet, Stockholm, Sweden

Kabir Sheikh

Public Health Foundation of India, New Delhi, India

Follow this and additional works at: https://ecommons.aku.edu/pakistan_fhs_mc_chs_chs Part of the Public Health Commons

\section{Recommended Citation}

Zaidi, S., Saligram, P., Ahmed, S., Sonderp, E., Sheikh, K. (2017). Expanding access to healthcare in South Asia. BMJ, 357(j1645), 1-4. Available at: https://ecommons.aku.edu/pakistan_fhs_mc_chs_chs/348 


\title{
Expanding access to healthcare in South Asia
}

\author{
Policy initiatives aiming to improve access to healthcare in South Asia have proliferated \\ in recent years, but are they enough to address widespread health inequity in the region, \\ ask Shehla Zaidi and colleagues?
}

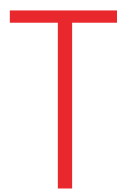

he South Asian region is faced with some of the world's worst socioeconomic inequities, and these compound widespread gaps in access to healthcare. ${ }^{1}$ Although there is a fairly extensive body of literature on the disparities that contribute to health inequity and their effect on health outcomes, less is known about the response from policy makers in South Asia.

As the commitment to universal health coverage (UHC) gains increasing global momentum, ${ }^{2}$ regional initiatives for expanding health access for poor people have risen up the policy agenda, and universal coverage forms the overarching framework for health targets in the sustainable development goals. ${ }^{3}$ Equitable access can be accelerated by health ministries through action on financing, governance, or human resources to direct health resources towards poor people ${ }^{45}$ or through action on social determinants of health. ${ }^{6}$

In this article, we focus on the recent proliferation of policy initiatives in South Asia aimed at making access to healthcare more equitable. These initiatives typically involve insurance schemes and contracting of private sector services. Insurance schemes partially or fully subsidised by the government are thought to improve access through risk pooling and reducing point of service payments. ${ }^{7}$ The unpredictability of healthcare needs, rising costs of treatment, and underlying poverty have given impetus to use of insurance. Strategic contracting of services through formal agreements between health ministries and the private sector, funded by government budgets, is increasingly being used to fill coverage gaps in disadvantaged areas. $^{8}$

Pulling together the main commonalities across the region, as well as underlining contextual differences, we look at three areas: existing policy initiatives and their underlying drivers and scale of implementation; equity, in terms of who is targeted and the extent and depth of coverage; and whether responses are integrated within health systems or standalone initiatives.

Our review is limited to Afghanistan, Pakistan, Bangladesh, and India, comprising 97\% of the South Asian population. ${ }^{9}$ We based our review on the insights of regional experts drawn from each of the four

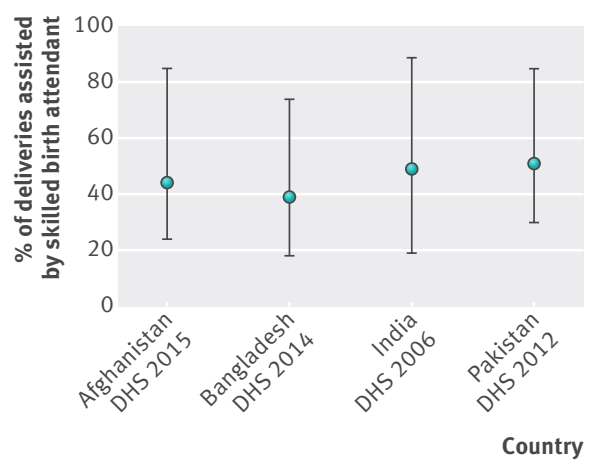

Fig 1 | Inequalities between richest, middle, and poorest quintiles in delivery assisted by skilled birth attendant in selected South Asian countries

countries and a scoping review of grey and published literature.

\section{Inequities in South Asian healthcare}

In South Asia coverage of even basic health interventions such as skilled birth attendance (fig 1), routine childhood immunisations, and use of family planning differ widely between the lowest and highest socioeconomic quintiles. This translates into lower life expectancy, higher morbidity, and undernutrition in those with low socioeconomic status. ${ }^{10-14}$ Uneven coverage cannot be narrowly equated to socioeconomic status but is also driven by urban-rural disparities. Rural areas have fewer functional health services and the population experiences barriers to access from the need to travel long distances and inadequate transport services, gender disparities, and low health knowledge. Financial access is indirectly measured by out-of-pocket spending and comprises as much as $56 \%$ of total health expenditure in Pakistan, 62\% in India, 64\% in Afghanistan, and 67\% in Bangladesh. ${ }^{15}$ This is often because inadequate government services force people to rely on the private sector and they also have to buy medicines when government clinics are out of stock. Social and private health insurance are limited in South Asia, ranging from 0\% of total health expenditure in Afghanistan to $7.7 \%$ in India. ${ }^{16}$

Understanding the complex and pluralistic health provider market in South Asia is important, since it is strongly segmented on the basis of services provided. The public sector and the large hybrid non-government sector have developed in silos, and lack of stewardship has led to frequent overlaps in service provision. There is a fairly extensive government health infrastructure providing free services to people from all income brackets but quality of care is poor, especially in more remote areas. However, it remains the main source of preventive healthcare across all groups and is often the main provider of hospital services for poor people. The private medical sector is mainly concentrated in urban areas, providing primary and hospital services to all income groups, with low emphasis on preventive care. ${ }^{17}$ A large informal private sector thrives in low income areas because of gaps in government service provision, often with paramedics and midwives practising as "doctors" as well as holding government jobs. ${ }^{18}$ Local and international non-profit organisations have become important suppliers of health care in Bangladesh, India, Pakistan, and Afghanistan. ${ }^{19-21}$

\section{Recent policy initiatives}

Government sponsored initiatives that attempt to expand health access to poor and disadvantaged communities have emerged in all four countries (box 1). The initiatives fall into two types-contracting and insurance-with both having a split between the financing and health provision functions of government.

The first set of initiatives started in the early to mid-2000s and involved govern ments formally contracting the private sector to provide free health services in underserved areas. For example, in Afghanistan there was a strong political imperative to provide health coverage quickly after the war by contracting international and local NGOs under government stewardship. ${ }^{2425} \mathrm{~A}$ different form of private sector contracting is seen in Pakistan, where the aim is to improve the functioning of government services in order to encourage poor people to return to using free government health services. It has taken the shape of management contracts for government primary care clinics implemented at scale and is now being applied to secondary hospitals as well as entire disadvantaged districts. In India contracting is being used to fill niche gaps in service coverage in low income areas. ${ }^{26-28}$ In Bangladesh contracting by the government is relatively small in scale and 
limited to the provision of primary healthcare services in slums across four cities. ${ }^{29}$ Whereas in Afghanistan contracting was driven by the international community advising the nascent health ministry, in Pakistan and India it has been led by subnational governments to improve governance of basic services with a focus on the poor.

The second set of initiatives are government financed health insurance schemes, seen in India, Pakistan, and Bangladesh. The main premise of these schemes has been to provide financial protection for the poor by providing "free" hospital cover usually at both government and private hospitals. The impetus has been led and financed by the central governments, with varying involvement by subnational governments. In India the first insurance scheme, Rashtriya Swasthya Bima Yojana, began in 2007-08, being implemented in 457 out of 687 districts, mainly in states that have agreed to cofinance the scheme. ${ }^{30-32}$ Pakistan launched its Prime Minister's insurance

Box 1: Examples of state funded initiatives providing health access for disadvantaged populations

\section{Afghanistan}

Basic and essential packages of health services-Started in 2002. It covers preventive, primary, and hospital care in 34 provinces. Implemented by Ministry of Health with help from World Bank, European Commission, and USAID

\section{Bangladesh}

Shasthya Shurokhsha Kormosuchi (SSK) -Started in 2015. Secondary care hospital services in three subdistricts of Tangail district. Implemented by: Ministry of Health and Family Welfare and district government

\section{India}

Rashtriya Swasthya Bima Yojana-Started in 2008. It provides inpatient treatment in select states and districts in India. Implemented by federal government, state governments, insurance company, and private and public facilities

Vajpayee Arogyashree Scheme-Started in 2009. Tertiary care. Implemented by Karnataka government, Suvarna Arogya Suraksha Trust, public and private hospitals

Rajiv ArogyaSri Community Health Insurance Scheme-Started in 2007 for tertiary care. Implemented by Andhra Pradesh government, third party administrator, insurer, public and private hospitals

Chiranjeevi scheme-Started in 2005. Contracting for maternity services in Gujarat. Implemented by state government, private providers

Haryana Urban $\mathrm{RCH}-$ Started in 2006. Reproductive and child health services to urban low income groups Haryana. State government and private providers

Family Planning Services I \& II-Started in 2005 and 2007. Contracting for family planning services in disadvantaged areas through private outlets. Karnakata \& Bihar. Implemented by central government, state governments, NGOs, private health facilities

Janani Soraksha Yogana-Started in 2003. Cash transfer for maternity services for low income women. Implemented by central government, district authorities, private providers

\section{Pakistan}

Prime Minister's national health scheme-Started in 2014. Hospital tertiary and secondary services in 19 out of 128 districts. Implemented by National Health Ministry, provincial governments, insurer, public and private hospitals ${ }^{22}$

Public-private partnerships for management of district, Tehsil hospitals and rural health centres-Started in 2012. Secondary and primary care services in three provinces, disadvantaged districts. Implemented by provincial governments, NGOs, private hospitals and philanthropic donation ${ }^{23}$

People's Primary Healthcare Initiative-Started in 2005. Management of government basic health units in all provinces, 82 districts. Implemented by provincial governments and rural support programmes access has varied depending on contractual design and incentives. In Afghanistan contracting started with a basic health package of services that provided for the needs of poor people, there is now an "essential package of hospital services," annual monitoring of quality and output through balanced score cards, and sharing of risk between NGOs and government with a proportion of funds tied to results. ${ }^{33}$ As a result Afghanistan's coverage of free services is better than some of the neighbouring countries, which has helped it meet the millennium goal target for reducing child mortality and almost meet the target for reducing maternal mortality. ${ }^{34}$ In Pakistan, general curative care services have increased while preventive services show little change, and there is questionable adherence to standard care guidelines. ${ }^{35}$ However, there is some evidence that contracted basic health units are better used by people in the bottom socioeconomic quintile. ${ }^{36}$ India and Bangladesh show improvement in maternity care coverage to the poor where targets have been specifically defined, although results on quality are mixed. 2729

Insurance schemes in India, Pakistan, and Bangladesh have explicitly targeted those below the poverty line. However, problems with selection of eligible people have been reported in India ${ }^{37}$ and may also be found in other schemes. A more systematic system to determine people below the poverty line is in operation in Pakistan, where a poverty score card has been refined through multiple surveys and donor assistance. ${ }^{35}$ In India informal workers' categories (autoworkers, hawkers, etc) have been added to the eligibility list as a proxy for those in need while Bangladesh is planning to extend coverage to contractual garment workers in 2017. The focus is primarily on hospital care and involves prespecified hospital treatments in designated facilities. Insurance schemes, with the exception of the recent Bangladesh pilot, lack coverage and gatekeeping links with preventive and primary care services. Such links are necessary to reduce the need for hospital care and length of stay, and are important for reducing the burden of disease in lower socioeconomic quintiles.

The cost of annual health insurance cover ranges from about $\$ 500$ ( $€ 400$; €480) per household in India and Pakistan to $\$ 630$ per household in Bangladesh. Transport costs are either not reimbursed or inadequately funded-for example, in Pakistan transport can cost as much as \$30-70 in rural remote areas, but the insurance scheme only provides a budget of $\$ 3$ per episode for transport. ${ }^{38} 39$ Evidence from India's longer running scheme has shown high out-ofpocket expenses and exhaustion of 
insurance cover because of unnecessary hospital use and health providers substituting high cost treatment for lower cost options. ${ }^{40}$ Awareness and enrolments in the scheme have also been lower in more disadvantaged groups, ${ }^{41}$ and need to be examined in other schemes. An Indian cash transfer scheme for maternity services did result in improved maternity care coverage, but evidence suggests the poorest populations benefited less than those who were moderately poor. ${ }^{42}$

\section{Well integrated and sustainable?}

Recent initiatives to expand healthcare access have been driven first by political imperatives, and only later incorporated country health strategies and policies. Universal health coverage with financial protection for people below the poverty line is emphasised in Bangladesh's current policies ${ }^{4344}$ but in Afghanistan there is a focus on increasing donor coordination into a single programme to strengthen the current system. Pakistan shows a dichotomous picture since devolution with federally led policies emphasising social protection for health and provincial led initiatives emphasising a strengthened public system..$^{45}$ There is also a mixed picture at the federal level in India, with the National Health Mission strengthening the public sector while federally financed insurance schemes focus on third party payers.

A major challenge, particularly for insurance programmes, is the lack of integration with provincial health initiatives on public financing, administration, regulation, and primary healthcare. For example, in Pakistan, since devolution provinces have substantially increased hospital budgets for medicines, supplies, and renovations-the insurance payment to hospitals therefore creates a duplicate funding line. Similarly, in all these countries existing hospital autonomy and capacity is insufficient to meet demand and make quality improvements, with a need for administrative

\section{Box 2: Research needs}

\section{Design}

- Scoping and feasibility studies to inform design of schemes

- Review of administrative, financing, and monitoring best practices related to insurance, contracting, cash transfers, vouchers for poor people

- Global reviews on incorporating client feedback and accountability in implementation of schemes

- Patient expenditure and utilisation surveys

\section{Implementation}

- Performance assessments including patient enrolment, utilisation, and expenditure using before-after with control/quasi-experimental design

- Quality of care assessments of government and private providers

- Exploratory studies of clients' barriers to utilisation of pro-poor schemes

- Policy analysis and governance studies on ongoing schemes

- Public financing analysis struggle in reducing health inequities, unless existing challenges are met head on.

The foremost challenge is that the construct of equity is narrow and often politically whimsical. It needs to be widened to include all three dimensions of universal heathcare. Insurance packages often miss out unmet needs for primary care. Further expansion of coverage will need attention to quality of care and transportation costs. Financial protection will require some level of preferential targeting for government financed contracting arrangements while insurance schemes need cross-subsidisation with inclusion of higher income groups.

The second challenge relates to gaps in the evidence base. Existing evidence is usually geared around measurement of aggregate resources and outputs without differentiation between who is covered and who is left out. ${ }^{47}$ More segmented research is needed to inform design of equity initiatives through scoping and review studies as well as to inform implementation through quality of care, governance, and client barrier studies in addition to the more usual impact assessments (box 2).

Finally, equity initiatives are often standalone and require integration within the health system administrative, financing and regulatory frameworks. Dispersion of authority across federal, state, and local government stakeholders makes this coordination complex in larger South Asian countries.

Above all, state stewardship is necessary to plan, regulate, finance, and monitor equity across all sectors. With the exception of Afghanistan, South Asian countries are still sitting on the fence, following mixed policies and reluctant to invest in strengthening direct service provision approaches while at the same time faltering in building the strong stewardship architecture needed for accountable and robust purchasing and insurance approaches.

Contributors and sources: SZ and KS conceptualised the paper. SA contributed findings from Bangladesh, PS from India, ES from Afghanistan, and SZ from Pakistan. SZ took the lead in synthesis and write-up of the paper. All contributors commented on drafts and revisions of the paper. Shahzad Hussain and Atif Riaz at Aga Khan University Karachi helped with the literature review.

Competing interests: We have read and understood BMJ policy on declaration of interests and have no relevant interests to declare.

Provenance and peer review: Commissioned; externally peer reviewed.

Shehla Zaidi, associate professor 1,1

Prasanna Saligram, research scientist ${ }^{2}$

Syed Ahmed, professor ${ }^{3}$

Egbert Sonderp, senior health adviser 4

Kabir Sheikh, senior research scientist ${ }^{2}$

${ }^{1}$ Community Health Sciences and Women and Child Health Division, Aga Khan University, Karachi, Pakistan

${ }^{2}$ Public Health Foundation of India, New Delhi, India

3BRAC, Dhaka, Bangladesh 
4Karolinska Institutet, Stockholm, Sweden shehla.zaidi@aku.edu

1 Rannan-Eliya R. Review of the situation of equity in access to maternal and child health care in the Asia-Pacific region. 2008. https://www.unicef.org/ eapro/Unicef_VN_MNCH_Review_04-22.pdf

2 Frenk J, de Ferranti D. Universal health coverage: good health, good economics. Lancet 2012;380:862-4. doi:10.1016/S0140-6736(12)61341-5

3 Save the Children Fund. Universal health coverage: a commitment to close the gap. 2013. https://www. savethechildren.org.uk/sites/default/files/docs/ Universal_health_coverage_summary.pdf

4 Kutzin J. Health financing for universal coverage and health system performance: concepts and implications for policy. Bull World Health Organ 2013;91:602-11. doi:10.2471/BLT.12.113985.

5 World Health Organization. Health systems governance for universal health coverage. action plan department of health systems governance and financing. 2014. http://www.who.int/universal_health_coverage/ plan_action-hsgov_uhc.pdf

6 Marmot M. Universal health coverage and social determinants of health. Lancet 2013;382:1227-8. doi:10.1016/S0140-6736(13)61791-2

7 Bennett S, Gilson L. Health financing: designing and implementing pro-poor policies. DFID Health Systems Resource Centre, 2001.

8 Perrot J, Roodenbeke D. Strategic contracting for health systems and services. Transaction Publishers, 2012

9 World Bank. Total population data, 2015. http://data. worldbank.org/indicator/SP.POP.TOTL

10 National Institute of Population Studies, Macro International. Pakistan Demographic and Health Survey 2012-13. 2014. http://www.nips.org.pk/ abstract_files/PDHS\%20Final\%20Report\%20as\%20 of\%20Jan\%2022-2014.pdf

11 International Institute for Population Sciences, Macro International. National Family Health Survey (NFHS-3). 2005-06. 2007. http://dhsprogram.com/pubs/pdf/ FRIND3/FRIND3-Vol1andVol2.pd

12 National Institute of Population Research and Training. Bangladesh Demographic and Health Survey 2014. 2016. https://dhsprogram.com/pubs/pdf/FR311/FR311.pd

13 Central Statistics Organization, Ministry of Public Health, ICF International. Afghanistan Demographic and Health Survey 2015: key indicators. 2016. http://dhsprogram. com/what-we-do/survey/survey-display-471.cfm

14 Dreze J, Sen A. Putting growth in its place. Yojana 2012;56.

15 World Bank. OOP expenditure as \% of total health expenditure, 2014. http://data.worldbank.org/ indicator/SH.XPD.OOPC.TO.ZS

16 National Health Systems Resource Centre. National health accounts estimates for India 2013-14. http:// nhsrcindia.org/NATIONAL\%2OHEALTH\%20

ACCOUNTS\%20Estimates\%20for\%2OIndia-2013-14.pdf.

17 Sheikh K, George A, eds. Health providers in India: on the frontlines of change. Routledge, 2012.

18 Hipgrave DB, Hort K. Dual practice by doctors working in South and East Asia: a review of its origins, scope and impact, and the options for regulation. Health Policy Plan 2014;29:703-16. doi:10.1093/heapol/ czt053.
19 Sidel M. Recent research on philanthropy and the nonprofit sector in India and South Asia. Voluntas 2001:12:171. doi:10.1023/A:1011290703464.

20 Sabri B, Siddiqi S, Ahmed AM, Kakar FK, Perrot I. Towards sustainable delivery of health services in Afghanistan: options for the future. Bull World Health Organ 2007;85:712-8. doi:10.2471/BLT.06.036939.

21 Zaidi S, Gul X. NPO performance in reproductive health sector of low and meddle income countries: what is the influence of the wider policy context? Int I Develop Soc 2012;1:141-8doi:10.11634/216817831201206.

22 Prime Minister's National Health Program. PC-1 form. Planning Commission, government of Pakistan. 2014.

23 Herbert HK, Lee ACC, Chandran A, Rudan I, Baqui AH. Care seeking for neonatal illness in low- and middle-income countries: a systematic review. PLoS Med 2012;9:e1001183. doi:10.1371/journal.pmed.1001183.

24 Palmer N, Strong L, Wali A, Sondorp E. Contracting out health services in fragile states. BMJ 2006;332:718-21. doi:10.1136/bmj.332.7543.718.

25 Siddiqi S, Masud TI, Sabri B. Contracting but not without caution: experience with outsourcing of health services in countries of the Eastern Mediterranean Region. Bull World Health Organ 2006;84:867-75

26 Bhat R, Huntington D, Maheshwari S. Public-private partnership, contracting arrangements and managerial capacity to strengthen RCH programme implementation. IIMA Working Papers. 2007.

27 Bhat R, Mavalankar DV, Singh PV, Singh N. Maternal healthcare financing: Gujarat's Chiranjeevi Scheme and its beneficiaries. J Health Popul Nutr 2009;27:249 58. doi:10.3329/jhpn.v27i2.3367.

28 Mavalankar D, Singh A, Patel SR, Desai A, Singh PV. Saving mothers and newborns through an innovative partnership with private sector obstetricians: Chiranjeevi scheme of Gujarat, India. Int J Gynaecol Obstet 2009;107:271-6. doi:10.1016/j. ijgo.2009.09.008.

29 Cortez R. NGO contracting evaluation for the HNP sector in Bangladesh: evidence and policy options. South Asia Human Development Sector series No 7.World Bank, 2005.http://siteresources.worldbank. org/INTBANGLADESH/Resources/NGO_Contracting_ Rafael.pdf.

30 Rajasekhar D, Berg E, Ghatak M, Manjula R, Roy S Implementing health insurance: the rollout of Rashtriya Swasthya Bima Yojana in Karnataka. Econ Polit Wkly 2011;:46:56-63.

31 Mishra U. Not in the pink of health. Forbes India, 2013, uhc-india.org/downloadpdf.php?link=ForbesNotinthePinkofHealth.pdf.

32 Nandi SDR, Garg S, Sinha D, Sahu S, Mahobe R. Uncovering coverage: utilisation of the universal health insurance scheme, Chhattisgarh by women in slums of Raipur. Indian J Gend Stud 2016;23:43-68doi:10.1177/0971521515612863.

33 Edward A, Kumar B, Kakar F, Salehi AS, Burnham G, Peters DH. Configuring balanced scorecards for measuring health system performance: evidence from 5 years' evaluation in Afghanistan. PLoS Med 2011;8:e1001066. doi:10.1371/journal. pmed.1001066.

34 United Nations. Country profile: Afghanistan. 2015. www.data.un.org/CountryProfile.aspx.
35 Martinez J, Pearson M, England R, et al. Third-party evaluation of the PPHI in Pakistan. DFId-HLSP.Technical Resource Facility and SOSEC, 2010.

36 Loevinsohn B, Haq IU, Couffinhal A, Pande A Contracting-in management to strengthen publicly financed primary health services--the experience of Punjab, Pakistan. Health Policy 2009;91:17-23. doi:10.1016/j.healthpol.2008.10.015.

37 Ghosh S, Mladovsky P. Social exclusion and its effect on enrolment in Rashtriya Swasthya Bima Yojana in Maharashtra, India. Towards equitable coverage and more inclusive social protection in health. 32. ITG Press, 2014.

38 National Health Accounts Pakistan. 2011-12. Pakistan bureau of statistics. Government of Pakistan. http:// www.pbs.gov.pk/sites/default/files/national_ accounts/national\%20health\%20accounts/ NHA_Report_2011-12.pdf

39 Zaidi S, Saeed A, Memon Z, Agha A, Haider G. Result based financial mechanisms for improving maternal, newborn and child health outputs: feasibility study for 10 NPPI districts. 2009. www.researchcollective.org/ Documents/NPPI\%20FFS.pdf

40 Selvaraj S, Karan A, Mukhopadhyay I. Publicly-financed health insurance schemes in India: How effective are they in providing financial risk protection. Social Development Report 2014

41 Ghosh S. Publicly-financed health insurance for the poor: understanding RSBY in Maharashtra. Econ Polit Wkly 2014;49(43-44).

42 Lim SS, Dandona L, Hoisington JA, James SL, Hogan MC, Gakidou E. India's Janani Suraksha Yojana, a conditional cash transfer programme to increase births in health facilities: an impact evaluation. Lancet 2010;375:2009-23. doi:10.1016/ S0140-6736(10)60744-1.

43 Adams AM, Ahmed T, El Arifeen S, Evans TG, Huda T, Reichenbach L. Lancet Bangladesh Team. Innovation for universal health coverage in Bangladesh: a call to action. Lancet 2013;382:2104-11. doi:10.1016 S0140-6736(13)62150-9.

44 Huda T, Khan JAM, Ahsan KZ, Jamil K, El Arifeen S. Monitoring and evaluating progress towards Universal Health Coverage in Bangladesh. PLoS Med 2014;11:e1001722. doi:10.1371/journal.pmed. 1001722

45 Ministry of National Health Services, Regulations and Coordination. National Health Vision Pakistan 2016-2025. http://www.nationalplanningcycles.org/ sites/default/files/planning cycle repository/ pakistan/national_health vision_2016-25_30-08-2016.pdf

46 Haidari AM, Zaidi S, Gul R. Prospects for the sustainability of delivering the Basic Package of Health Services in Afghanistan: a stakeholder analysis. East Mediterr Health / 2014;20:300-8

47 Jacobs B, Ir P, Bigdeli M, Annear PL, Van Damme W. Addressing access barriers to health services: an analytical framework for selecting appropriate interventions in low-income Asian countries. Health Policy Plan 2012;27:288-300. doi:10.1093/heapol/ czr038.

Cite this as: BMJ 2017;357:j1645 http://dx.doi.org/10.1136/bmj.j1645 